\title{
Follow-up Study on Electroconvulsive Therapy in Treatment-resistant De- pressed Patients after Remission: A Chart Review
}

Yuki Tokutsu, Wakako Umene-Nakano, Takahiro Shinkai, Reiji Yoshimura, Tatsuya Okamoto, Asuka Katsuki, Hikaru Hori, Atsuko Ikenouchi-Sugita, Kenji Hayashi, Kiyokazu Atake, Jun Nakamura

Department of Psychiatry, School of Medicine, University of Occupational and Environmental Health, Fukuoka, Japan

\begin{abstract}
Objective: Electroconvulsive therapy (ECT) has proven to be effective in treatment-resistant depression (TRD). In recent reports, $70 \%$ to $90 \%$ of patients with TRD responded to ECT. However, post-ECT relapse is a significant problem. There are no studies investigating risk factors associated with reintroducing ECT in depressive patients after remission previously achieved with former ECT. The aim of the present study is to examine such risk factors using a sample of TRD patients.

Methods: We conducted a chart review to examine patient outcomes and adverse events over short- and long-term periods. Forty-two patients met the criteria for major depressive disorder.

Results: The response rate was 85.7\% (36/42). There were no significant differences in the baseline characteristics of patients exhibiting remission, response or non-response. The rate of adverse events was 21.4\% (9/42). Among 34 patients who were available for follow-up, 18 patients relapsed (relapse rate, 52.9\%), and 6 patients were reintroduced to ECT. The patients' age and age of onset were significantly higher in the re-ECT group than non re-ECT group.

Conclusion: Our results suggest that older age and older age of onset might be considered for requirement of re-ECT after remission previously achieved with former ECT.
\end{abstract}

KEY WORDS: Electroconvulsive therapy; Treatment resistant depression; Aging; Drug therapy.

\section{INTRODUCTION}

Electroconvulsive therapy (ECT) has proven effective in the treatment of major depressive disorder ${ }^{1)}$ and especially treatment-resistant depression (TRD). ${ }^{2,3)}$ Several recent reports have shown that $70 \%$ to $90 \%$ of patients with TRD responded to ECT. ${ }^{4-7)}$ Though the short-term efficacy of ECT is reported to be high, relapse rates are also high. $^{8-10)}$ Therefore, maintenance and continuation of ECT for a period of roughly 6 months has been recommended. ${ }^{11,12)}$ According to the guidelines for ECT published in the United Kingdom by the National Institute for Health and Clinical Excellence, the long-term benefits and risks of maintenance ECT have not been clearly established. In a clinical setting, antidepressants can be administered on a short-term basis after initial ECT

\footnotetext{
Received: August 24, 2012 / Revised: October 8, 2012

Accepted: November 5, 2012

Address for correspondence: Wakako Umene-Nakano, MD, PhD Department of Psychiatry, School of Medicine, University of Occupational and Environmental Health, 1-1 Iseigaoka, Yahatanishi-ku, Kitakyushu. Fukuoka 8078555, Japan

Tel: +81-936917253, Fax: +81-936924894

E-mail: wakako-u@med.uoeh-u.ac.jp
}

treatment. However, once patients have relapsed or experienced recurring depressive episodes after the first ECT session, reintroduction of ECT should be considered. Although ECT is generally considered a safe procedure, no existing research has investigated the risks and benefits associated with reintroducing ECT. In this study, we conducted a chart review to examine the short-term effects and adverse events associated with ECT, the long-term effects after 1 year, and the factors involved in reintroducing ECT for patients exhibiting TRD.

\section{METHODS}

A systematic chart review was conducted at the Department of Psychiatry, School of Medicine, University of Occupational and Environmental Health (UOEH), Japan. ECT was conducted in the psychiatric ward of the University hospital from January 2005 to December 2010 for 56 patients who had been diagnosed with major depressive disorder ( $\mathrm{F} 32$ or F33 according to the International Classification of Disease, 10th edition). TRD was defined as a failure to respond to adequate trials of 2 dis-

(c) This is an Open-Access article distributed under the terms of the Creative Commons Attribution Non-Commercial License (http://creativecommons.org/licenses/by-nc/3.0) which permits unrestricted non-commercial use, distribution, and reproduction in any medium, provided the original work is properly cited. 
tinctly different classes of antidepressants (stage II definition from Thase and Rush ${ }^{13)}$ ). The recorded patient information included age, sex, number of past admissions, duration of illness and current episode, time to relapse or recurrence, time to readmission, past and current suicide attempts, presence of psychotic symptoms and the number of ECT sessions. A patient's outcome was measured 1 year after the final ECT treatment was given.

Forty-four of 56 patients with TRD were diagnosed with major depressive disorder, and data from 42 of the 44 patients $(\mathrm{F} 32=10 ; \mathrm{F} 33=32)$ were included, as 2 patients did not complete the ECT treatment course. Background information on the subjects is presented in Table 1. The antidepressants used and number of subjects treated with each were paroxetine $(n=9)$, sertraline $(n=8)$, mirtazapine $(n=5)$, milnacipran $(n=4)$, duloxetine $(n=4)$, fluvoxamine $(\mathrm{n}=1)$, and other medications $(\mathrm{n}=11)$.

A physical examination, blood and urine examinations, electrocardiogram, cerebral computed tomography scan and chest film were used to assess each patient's general medical condition. Each subject received premedication including atropine sulfate $(0.5 \mathrm{mg}$ i.v. $)$, propofol (1.0 $\mathrm{mg} / \mathrm{kg}$ i.v.), vecuronium (0.5-1.0 mg i.v.) and succinylcholine (1.0 mg/kg i.v.). ECT was performed between 7:00 and 9:00 AM using a Thymatron TM DG (Somatics Inc., Lake Bluff, IL, USA) with standard settings ${ }^{14)}$ and a brief bipolar square wave pulse. The patients were given bilateral ECT with two stimulus electrodes placed over the left and right frontotemporal scalp. ECT conditions

Table 1. Background of subjects $(n=42)$

\begin{tabular}{lc}
\hline \multicolumn{1}{c}{ Chracteristic } & Data \\
\hline Age (year) & $61.3 \pm 13.6(27-81)$ \\
Gender & $6(38.1)$ \\
Male & $26(61.9)$ \\
Female & \\
Diagnosis (ICD-10) & 10 \\
F32 & 32 \\
F33 & $7.4 \pm 8.9$ \\
Duration of illness (year) & $53.3 \pm 16.3$ \\
Age at onset (year) & $9.7 \pm 10.7$ \\
Duration of current episode (month) & $21.9 \pm 5.9$ \\
HAMD-17 at start & $13(31.0)$ \\
Patients with psychotic symptoms & $8(19.1)$ \\
History of past suicide attempts & $1.2 \pm 1.0$ \\
Number of past administrations & $10.5 \pm 2.8$ \\
Number of ECT & $130.2 \pm 58.8(10-225)$ \\
Dose of antidepressant & \\
(imipramine equivalent) &
\end{tabular}

Values are presented as mean \pm standard deviation (range), or number (\%). ICD-10, International Classification of Disease, 10th edition; HAMD-17, Hamilton Rating Scale for Depression; ECT, electroconvulsive therapy. were identical for all patients (maximum charge delivered $504 \mathrm{mC}$, current $0.9 \mathrm{~A}$, frequency $10-70 \mathrm{~Hz}$, pulse width $0.5 \mathrm{~ms}$, maximum duration $8 \mathrm{~s}$ ). Motor convulsions, electroencephalograms, induced tachycardia and electromyograms were monitored during ECT as necessary. ECT was administered 12 times (three times a week for four weeks). Patients were placed on drug treatment for at least one week before ECT, and drug treatment was maintained during the entire study period. After ECT, patients were seen in outpatient setting.

Depressive symptoms were clinically evaluated using scores on the 17-item version of the Hamilton Rating Scale for Depression (HAMD-17) ${ }^{15)}$ before and after ECT treatment. Each attending psychiatrists for each patients assessed HAMD-17 within a week after final ECT. Remission was defined as a HAMD-17 score below 7, and response was defined as a final HAMD-17 score improvement of at least $50 \%$ compared to baseline. We also defined relapse or recurrence of depressive state as HAMD-17 scores of 15 or more.

The Mann-Whitney U-test and Fisher's exact test were used to statistically compare the measured variables of 2 groups, and Tukey's post-hoc tests were used in conjunction with analysis of variance (ANOVA) to compare the measured variables of 3 groups. A result was considered to be statistically significant at $p \leq 0.05$. This study was approved by the Institutional Review Board at UOEH and was exempted from the requirement for informed consent because the study involved deidentified data acquired during routine care.

\section{RESULTS}

Twenty-three patients (54.8\%) experienced a remission, 13 exhibited a response to treatment, and 6 presented non-response. The overall response rate (including remissions) was $85.7 \%$. There were no significant differences in the baseline characteristics of the remission, response and non-response groups (Table 2). Nine patients (21.4\%) experienced adverse events, including delirium $(\mathrm{n}=5)$, amnesia $(\mathrm{n}=2)$, headache $(\mathrm{n}=1)$ and galactopoiesis $(\mathrm{n}=1)$ during continuation ECT.

We were able to follow up on 34 patients 1 year after ECT treatment (8 patients went to other department) and found that 12 patients were stable, 18 patients $(52.9 \%)$ had relapsed and 4 patients $(11.8 \%)$ had experienced a recurrence. All patients continued only antidepressant treatment with sertraline $(n=8)$, mirtazapine $(n=7)$, paroxetine $(n=5)$, duloxetine $(n=5)$, milnacipran $(n=3)$, fluvox- 
Table 2. Differences in clinical course

\begin{tabular}{lccc}
\hline \multicolumn{1}{c}{ Characteristic } & Remission & Responders & Non-responders \\
\hline Patients & 23 & 13 & 6 \\
Age (year) & $57.8 \pm 14.7$ & $66.8 \pm 12.1$ & $62.7 \pm 11.8$ \\
Percentage of males & 43.8 & 31.3 & 25.0 \\
Duration of illness (year) & $6.7 \pm 5.3$ & $8.4 \pm 13.8$ & $7.8 \pm 8.0$ \\
Age at onset (year) & $51.3 \pm 14.9$ & $56.1 \pm 19.7$ & $55.0 \pm 14.7$ \\
Duration of current episode (month) & $9.4 \pm 11.2$ & $9.8 \pm 9.8$ & $10.3 \pm 12.8$ \\
HAMD-17 at start & $20.6 \pm 5.9$ & $25.0 \pm 6.0$ & $0.247^{\dagger}$ \\
Patients with psychotic symptoms (\%) & 69.2 & 30.7 & $0.853^{*}$ \\
Number of past administrations & $1.2 \pm 1.0$ & $1.1 \pm 1.0$ & $0.690^{*}$ \\
\hline
\end{tabular}

Values are presented as number or mean \pm standard deviation. *By analysis of variance (ANOVA), post-hoc Tukey. ${ }^{\dagger}$ Fisher's exact test, post-hoc Tukey. HAMD-17, Hamilton Rating Scale for Depression.

Table 3. Comparison among patients with and without reintroduction of ECT

\begin{tabular}{|c|c|c|c|}
\hline & Re-ECT & Non re-ECT & $p$ value \\
\hline Patients & 6 & 16 & \\
\hline Age (year) & $74.5 \pm 4.8$ & $60.4 \pm 12.5$ & $0.015^{*} \neq$ \\
\hline Percentage of males & 16.7 & 31.3 & $0.634^{\dagger}$ \\
\hline Duration of illness (year) & $4.2 \pm 6.8$ & $8.2 \pm 10.8$ & $0.086^{*}$ \\
\hline Age at onset (year) & $70.3 \pm 9.2$ & $50.3 \pm 14.8$ & $0.009^{*} \neq$ \\
\hline Duration of current episode (month) & $5.0 \pm 3.0$ & $8.6 \pm 9.6$ & $0.738^{*}$ \\
\hline HAMD-17 at start & $22.0 \pm 2.3$ & $22.1 \pm 6.0$ & $0.971^{*}$ \\
\hline Patients with psychotic symptoms (\%) & 16.7 & 25.0 & $1.000^{\dagger}$ \\
\hline Number of past administrations & $0.8 \pm 0.8$ & $1.3 \pm 1.1$ & $0.421^{*}$ \\
\hline Time to readmission (month) & $6.0 \pm 2.2$ & $2.8 \pm 2.7$ & $0.061^{*}$ \\
\hline Time to relapse or recurrence (month) & $4.2 \pm 2.7$ & $1.6 \pm 1.2$ & $0.023^{t, \dagger}$ \\
\hline $\begin{array}{l}\text { Dose of antidepressant } \\
\text { (imipramine equivalent) }\end{array}$ & $154.2 \pm 62.1$ & $143.8 \pm 49.4$ & $0.868^{\star}$ \\
\hline
\end{tabular}

${ }^{*}$ Mann-Whitney $U$ test, ${ }^{\dagger}$ Fisher's exact test, ${ }^{\dagger} p \leq 0.05$. ECT, electroconvulsive therapy; HAMD-17, Hamilton Rating Scale for Depression.

amine $(n=2)$ or other medications $(n=4)$. Six patients $(5$ patients were relapsed and 1 was recurrence) were reintroduced to ECT. All 6 patients with TRD were diagnosed with major depressive disorder (relapsed or reccurence), and they had not been conducted the ECT until these times. We compared the background factors of the patients who were reintroduced to ECT treatment (re-ECT group) and those not re-ECT (non re-ECT group) (Table 3 ). The mean age and age at onset of the depressive episodes of the re-ECT group were significantly higher than those of the non re-ECT group (age: re-ECT 74.5 \pm 4.8 years, non re-ECT $60.4 \pm 12.5$ years, $p=0.015$; age at onset: re-ECT $70.3 \pm 9.2$ years, non re-ECT $50.3 \pm 14.8$ years, $p=0.009$ ). The mean times to relapse and recurrence of the re-ECT group were significantly longer than those of the non re-ECT group (re-ECT 4.2 \pm 2.7 , non re-ECT 1.6 \pm 1.2 , $p=0.023$ ). The re-ECT group was treated but failed to respond to adequate trials of 2 distinctly different classes of antidepressants when they had a relapse or recurrence after the first ECT. The mean HAMD-17 scores of the re-ECT group on the 2 nd time ECT were $22.8 \pm 5.4$. The re- sponse rate was $66.7 \%$.

\section{DISCUSSION}

The major finding of this study was that elderly patients were more prone to relapse and recurrence, suggesting that older depressed patients may exhibit a greater degree of treatment resistance. Global predictors of TRD included comorbid axis I disorders and medical illnesses such as diabetes mellitus and hypertension. ${ }^{16)}$ It has been reported that ECT is more effective in older patients than in younger adult patients. ${ }^{17,18)}$ Accordingly, there have been many studies of ECT of elderly patients. ${ }^{19,20)}$ Older patients may tend toward ECT treatment as a result of continuation pharmacotherapy after ECT.

The response rate in patients with TRD was $85.7 \%$, which is similar to that reported in previous studies. 3 ,21-23) The patient demographics of the three groups (remission, response, and non-response) were not significantly different. Delirium was the most frequent adverse event with a rate of $12.5 \%$, similar to the rate observed in a previous 
study. ${ }^{24)}$ Watts et al. ${ }^{25)}$ have reported that the mortality rate of ECT is less than one death per 73,440 treatments, and the most commonly reported adverse events after ECT are injury to the mouth and problems related to paralysis. Other adverse events reported after ECT include cognitive dysfunction, delirium, memory impairment, headache and amnesia. We have also published a case report about galactopoiesis. ${ }^{26)}$ Strategies developed to decrease the incidence of post-ECT relapse include continuation ECT at biweekly or monthly intervals over 4 to 6 months and continuation pharmacotherapy after ECT. ${ }^{27)}$ In naturalistic follow-up studies, it has been reported that $51 \%$ of major depressive disorder patients who receive usual care with continuation antidepressants alone or in combination with lithium experienced a relapse within 6 months. ${ }^{28)}$ A prospective naturalistic study found a post-ECT relapse rate of $64.3 \%$ after 6 months, with a median time to relapse of 8.6 weeks. ${ }^{29)}$ The Health Technology Assessment Committee reported a relapse rate at 12 months of $33 \%$ for continuation ECT, $32 \%$ with lithium in combination with a tricyclic antidepressant, $56 \%$ with a tricyclic antidepressant and $72 \%$ without treatment. ${ }^{30)}$ The reported depression relapse rates with continuation ECT and continuation pharmacotherapy are $37.1 \%$ and $31.6 \%$, respectively. ${ }^{31)}$ In this study, all subjects were treated with continuation pharmacotherapy, and the relapse rate was $52.9 \%$. In this study, the response rate in the re-ECT group was $66.7 \%$. To the best of our knowledge, there is no study about response rate in reintroduction of ECT. It has been however reported that maintenance ECT might be useful for prevention of relapse and recurrence in chronically depressed patients who responded to acute treatment with $\mathrm{ECT}^{32)}$ Although the 6 patients in our study did not be selected to receive continued ECT, such treatment would have been beneficial for them. Possible limitations of this study include the small sample size and the retrospective chart review approach. Large prospective studies may identify precise factors characterizing TRD patients who may benefit from a reintroduction of ECT. In conclusion, $85.7 \%$ of patients experienced a short-term response to ECT, with a $21.4 \%$ incidence of adverse events. After a 1-year period of continuation pharmacotherapy, the long-term relapse rate was $52.9 \%$, and older patients were retreated with ECT more frequently than younger patients.

\section{REFERENCES}

1. Fink M. Convulsive therapy: a review of the first 55 years. J Affect Disord 2001;63:1-15.

2. Prudic J, Sackeim HA, Devanand DP. Medication resistance and clinical response to electroconvulsive therapy. Psychia- try Res 1990;31:287-296.

3. Devanand DP, Sackeim HA, Prudic J. Electroconvulsive therapy in the treatment-resistant patient. Psychiatr Clin North Am 1991;14:905-923.

4. Prudic J, Haskett RF, Mulsant B, Malone KM, Pettinati HM, Stephens S, et al. Resistance to antidepressant medications and short-term clinical response to ECT. Am J Psychiatry 1996;153:985-992.

5. Sackeim HA, Prudic J, Devanand DP, Nobler MS, Lisanby $\mathrm{SH}$, Peyser S, et al. A prospective, randomized, double-blind comparison of bilateral and right unilateral electroconvulsive therapy at different stimulus intensities. Arch Gen Psychiatry 2000;57:425-434.

6. McDonald WM. Is ECT cost-effective? A critique of the National Institute of Health and Clinical Excellence's report on the economic analysis of ECT. J ECT 2006;22:25-29.

7. Kennedy SH, Giacobbe P. Treatment resistant depression-advances in somatic therapies. Ann Clin Psychiatry 2007; 19:279-287.

8. Kellner $\mathrm{CH}$, Bourgon LN. Combining ECT and antidepressants: time to reassess. J ECT 1998;14:65-67.

9. Sackeim HA, Prudic J, Devanand DP, Kiersky JE, Fitzsimons L, Moody BJ, et al. Effects of stimulus intensity and electrode placement on the efficacy and cognitive effects of electroconvulsive therapy. N Engl J Med 1993;328:839-846.

10. Aronson TA, Shukla S, Hoff A. Continuation therapy after ect for delusional depression: a naturalistic study of prophylactic treatments and relapse. Convuls Ther 1987;3:251-259.

11. Frank E, Prien RF, Jarrett RB, Keller MB, Kupfer DJ, Lavori PW, et al. Conceptualization and rationale for consensus definitions of terms in major depressive disorder. Remission, recovery, relapse, and recurrence. Arch Gen Psychiatry 1991;48:851-855.

12. Gupta S, Tobiansky R, Bassett P, Warner J. Efficacy of maintenance electroconvulsive therapy in recurrent depression: a naturalistic study. J ECT 2008;24:191-194.

13. Thase ME, Rush AJ. When at first you don't succeed: sequential strategies for antidepressant nonresponders. $J$ Clin Psychiatry 1997;58(Suppl 13):23-29.

14. Abrams R, Swartz CM, Vedak C. Antidepressant effects of right versus left unilateral ECT and the lateralization theory of ECT action. Am J Psychiatry 1989;146:1190-1192.

15. Hamilton M. A rating scale for depression. J Neurol Neurosurg Psychiatry 1960;23:56-62.

16. Trivedi MH. Treatment-resistant depression: new therapies on the horizon. Ann Clin Psychiatry 2003;15:59-70.

17. Petrides G, Fink M, Husain MM, Knapp RG, Rush AJ, Mueller $\mathrm{M}$, et al. ECT remission rates in psychotic versus nonpsychotic depressed patients: a report from CORE. J ECT 2001;17:244-253.

18. O'Connor MK, Knapp R, Husain M, Rummans TA, Petrides G, Smith G, et al. The influence of age on the response of major depression to electroconvulsive therapy: a C.O.R.E. Report. Am J Geriatr Psychiatry 2001;9:382-390.

19. Tominaga K, Okazaki M, Higuchi H, Utagawa I, Nakamura E, Yamaguchi N. Symptom predictors of response to electroconvulsive therapy in older patients with treatment-resistant depression. Int J Gen Med 2011;4:515-519.

20. Gardner BK, O'Connor DW. A review of the cognitive effects of electroconvulsive therapy in older adults. J ECT 2008;24: 68-80.

21. Husain SS, Kevan IM, Linnell R, Scott AI. Electroconvulsive therapy in depressive illness that has not responded to drug treatment. J Affect Disord 2004;83:121-126.

22. Bailine SH, Rifkin A, Kayne E, Selzer JA, Vital-Herne J, 
Blieka M, et al. Comparison of bifrontal and bitemporal ECT for major depression. Am J Psychiatry 2000;157:121-123.

23. Sackeim HA, Haskett RF, Mulsant BH, Thase ME, Mann $\mathrm{JJ}$, Pettinati HM, et al. Continuation pharmacotherapy in the prevention of relapse following electroconvulsive therapy: a randomized controlled trial. JAMA 2001;285:1299-1307.

24. Kikuchi A, Yasui-Furukori N, Fujii A, Katagai H, Kaneko $\mathrm{S}$. Identification of predictors of post-ictal delirium after electroconvulsive therapy. Psychiatry Clin Neurosci 2009; 63:180-185.

25. Watts BV, Groft A, Bagian JP, Mills PD. An examination of mortality and other adverse events related to electroconvulsive therapy using a national adverse event report system. J ECT 2011;27:105-108.

26. Tokutsu Y, Umene-Nakano W, Yoshimura R, Katsuki A, Atake K, Nakamura J. The case of a depressed man who exhibited hyperprolactinemia and galactopoiesis after electroconvulsive therapy. J ECT 2012;28:56.

27. Russell JC, Rasmussen KG, O'Connor MK, Copeman CA, Ryan DA, Rummans TA. Long-term maintenance ECT: a retrospective review of efficacy and cognitive outcome. $J$ ECT 2003;19:4-9.

28. Tew JD Jr, Mulsant BH, Haskett RF, Joan P, Begley AE,
Sackeim HA. Relapse during continuation pharmacotherapy after acute response to ECT: a comparison of usual care versus protocolized treatment. Ann Clin Psychiatry 2007; 19:1-4.

29. Prudic J, Olfson M, Marcus SC, Fuller RB, Sackeim HA. Effectiveness of electroconvulsive therapy in community settings. Biol Psychiatry 2004;55:301-312.

30. Greenhalgh J, Knight C, Hind D, Beverley C, Walters S. Clinical and cost-effectiveness of electroconvulsive therapy for depressive illness, schizophrenia, catatonia and mania: systematic reviews and economic modelling studies. Health Technol Assess 2005;9:1-156, iii-iv.

31. Kellner CH, Knapp RG, Petrides G, Rummans TA, Husain $\mathrm{MM}$, Rasmussen $\mathrm{K}$, et al. Continuation electroconvulsive therapy vs pharmacotherapy for relapse prevention in major depression: a multisite study from the Consortium for Research in Electroconvulsive Therapy (CORE). Arch Gen Psychiatry 2006;63:1337-1344.

32. Gagné GG Jr, Furman MJ, Carpenter LL, Price LH. Efficacy of continuation ECT and antidepressant drugs compared to long-term antidepressants alone in depressed patients. Am J Psychiatry 2000;157:1960-1965. 